\title{
Influence of varying colour intensity on the perceived sweetness in yoghurt
}

\author{
J. Giovanni, H. Al-Kateb, H. Flaherty and V. Cox \\ Faculty of Health and Life Sciences, Coventry University, Coventry CV1 5FB, UK
}

Various efforts to reduce the UK's sugar consumption have been done, and yet sugar intake still exceeds the recommended intake level (i.e. $5 \%$ of total dietary energy $)^{(1)}$. Colour has been highlighted as influencing taste perception, including sweetness ${ }^{(2)}$. This gives rise to the theoretical possibility that colour could be a solution. Past studies looking at the colour-sweetness relationship in beverages showed conflicting results hence this relationship remains inconclusive ${ }^{(3,4)}$, and little is known about effects in yoghurt. This study, therefore, aimed to investigate the influence of colour intensity on perceived sweetness in yoghurt. Following an ethical approval given by Coventry University Ethics Committee, twenty healthy participants (aged 18-25 years old, mean BMI $=22.03 \mathrm{~kg} / \mathrm{m}^{2}$ ) were recruited to rate the perceived sweetness of unflavoured yoghurt samples containing different colour concentrations using a Labelled Affective Magnitude (LAM) scale, and were asked to state what flavour(s) they perceived (if there was any). Result of regression analysis (Figure 1) found a weak and non-significant relationship between colour intensity and perceived sweetness $(r=0 \cdot 007$, adjusted $\left.\mathrm{R}^{2}=-0.007, \mathrm{~F}_{1,138}=0.006, \mathrm{p}=0.939\right)$.

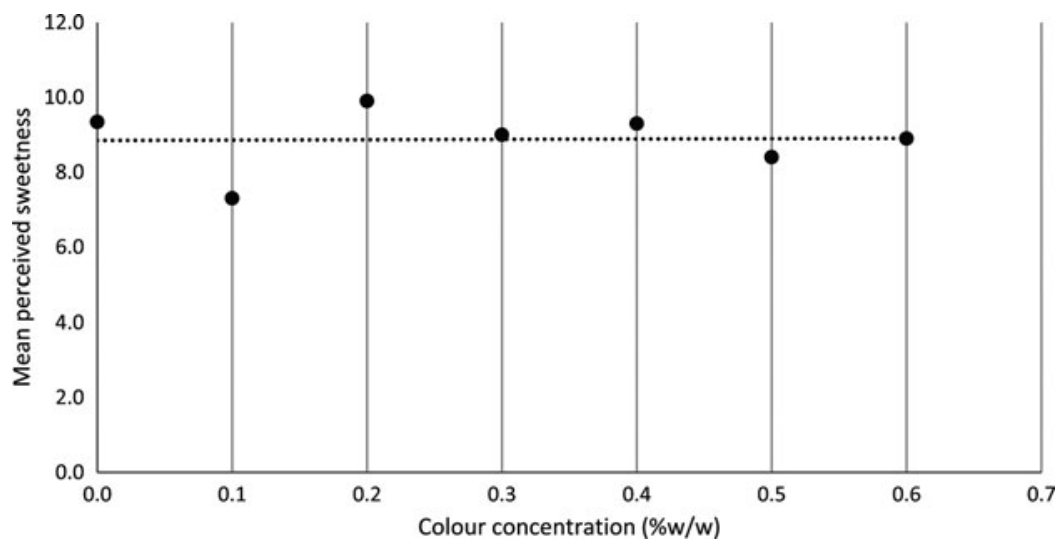

Fig. 1. The relationship between colour intensity and perceived sweetness. Dotted line represents the regression line.

It was also found that colour suggested flavour identity to some participants. This study is a small-scale undergraduate final year project. Therefore, a concrete conclusion of the colour-sweetness relationship cannot be drawn. More research needs to be done to investigate whether and to what extent colour influences sweetness perception. Better understanding on colour-sweetness relationship may potentially be useful in product development and improving public health as well as cost saving from sugar-related diseases.

1. Bates B, Cox L, Page SNP et al. (2016) National Diet and Nutrition Survey. Results from Years 5 and 6 (combined) of the Rolling Programme (2012/ 2013-2013/2014). London: Public Health England.

2. Fernandez-Vazquez R, Hewson L, Fisk I et al. (2014) Flavour 3, 4.

3. Spence C, Levitan CA, Shankar MU et al. (2010) Chem. Percept 3, 68-84.

4. Spence C (2015) Flavour 21, 4 